\title{
Study of First Principles of Mg-Si Binary Systems as Precipitates from T6 Heat Treatment of AL-MG-SI ALLOYS
}

\author{
Deni Haryadi, and Haris Rudianto* \\ Advanced Materials Laboratory, Department of Mechanical Engineering, Gunadarma University, Depok \\ "harisrudiato@staff.gunadarma.ac.id
}

\section{ABSTRACT}

One of the purposes adding the two main alloying elements $\mathrm{Si}$ and $\mathrm{Mg}$ in small quantities $(\approx 1 \%)$ on Aluminum is to form strengthening precipitates in aluminium alloy, which typically contribute with a fivefold strength increase from pure aluminum. In the last decades, the investigation has begun to understand the structure and formation of the different phases during heat treatment. An important precipitate in Al-Mg-Si Alloy is $\beta^{\prime \prime}$ and $\beta$. when the Precipitate $\beta$ is created after $\beta "$ is that the strength suddenly drops and the alloy is said to be overaged. By means of a first-principles supercell approach and density functional theory calculations, this research studied precipitate energy and interface energy of precipitate $\beta^{\prime \prime}$ and $\beta$. Results show that precipitate $\beta$ have precipitate energy higher then $\beta$ " but have interface energy lowers then $\beta "$. And each low energy interface was found possesses interface with the $\mathrm{Al}$ matrix is fully incoherent. The final result of calculation and simulation values for the interfacial energies, precipitate energies and strain energies that can be used in future predictions of the characteristic precipitate.

Keywords: Atomic simulation, Precipitate, Interface, First-principles, DFT, Quantum espresso, Aluminum.

\section{INTRODUCTION}

Aluminium is the third most abundant element in the Earth's crust, after oxygen and silicon and the second most used metal in the world after Steel ${ }^{[1]}$. Alumunium has several advantages in many cases: light weight (and high strength-to-weight ratio), good formability and machinability, excellent corrosion resistance, high thermal and electrical conductivity and Recycling of aluminium products needs only 5\% of the energy needed for primary aluminium production and infinite recyclability. Of special interest are $\mathrm{Al}-\mathrm{Mg}-\mathrm{Si}$ alloys, being the alloys of choice for medium-strength architectural and transportation applications, most prominently in the automotive industry ${ }^{[2,3]}$. The purpose of adding the two main alloying elements $\mathrm{Mg}$ and $\mathrm{Si}$ in small amounts $(\approx 1 \%)$ is to form hardening precipitates, which typically contribute with a fivefold strength increase from pure aluminium. Understanding the process of precipitation and how it affects mechanical properties have been important subjects of research for hundred years ${ }^{[4]}$. Only in the last decades we begun to understand the structure and formation of the different phases during heat treatment. There is a handful of discovered metastable phases in the $\mathrm{Al}-\mathrm{Mg}-\mathrm{Si}$ system alone. precipitates forming during aging at medium high temperatures (around $150{ }^{\circ} \mathrm{C}$ ) after Soluton Heat treatments (around between 400 and $500{ }^{\circ} \mathrm{C}$ ). And then Rapid cooling ensures a supersaturated solid solution (SSSS), after which the solutes start clustering in the face centred cubic Al lattice. The strength is caused by a high number density of nano-sized, needle-shaped $\beta^{\prime \prime}$ precipitates, usually together with Guinier-Preston (GP) zones. With increasing temperature and aging time, the number density decreases, while the precipitates coarsen and are replaced by more stable types. The precipitation sequence in $\mathrm{Al}-\mathrm{Mg}-\mathrm{Si}$ alloys is ${ }^{[3,4]}$.

$$
\text { SSSS } \rightarrow \text { Cluster } \rightarrow \text { GP-zones } \rightarrow \beta^{\prime \prime} \rightarrow \beta^{\prime}, \mathrm{U} 1, \mathrm{U} \text { 2, } \mathrm{B}^{\prime} \rightarrow \beta
$$


One of the key factors that control the mechanical properties of precipitate-hardened alloys is the precipitate morphology,i.e. the size and shape of precipitates. In order to predict ${ }^{[5,6]}$ the precipitate microstructural evolution and thus mechanical properties, it is critical that the thermodynamicdriving forces and kinetic mechanisms that lead to various precipitate shapes be understood. The morphology of a precipitate is primarily determined by two competing energetic contributions, i.e. the interfacial energy between the precipitate and the matrix and the coherency elastic strain energy generated due to the lattice mismatch between the precipitate and the matrix. Obtaining these quantities directly from experiments can be difficult due to the metastable nature of many precipitates. The main objective of this paper is to search for low energy interfaces between the precipitate and the $\alpha$-Al matrix from a firstprinciples approach. ${ }^{[7]}$

DFT has been used to support the experimental results and better explain the observed features in each alloy. Precipitate energies and Strain energy have been calculated for solute additions and structural variants of the $\beta^{\prime \prime}$ and $\beta$ phase ${ }^{[8]}$. We will do calculations on equillibrium structure of the different precipitate plus interfaces using Density Functional Theory (DFT) with the Quantum Espresso computer code. The simulation models for calculations, we create using Visualization For Electronic and Structural Analysis (VESTA).

\section{METHOD}

Density functional theory (DFT) has been shown to provide reliable energetics for aluminum and its alloys We have used self-consistent DFT as implemented in the Quantum ESPRESSO package $^{[4]}$. Quantum ESPRESSO is open-Source Package for Research in Electronic Structure, Simulation, and Optimization, is an integrated software suite for first-principle simulations, using density-functional theory (DFT), a plane waves (PW) basis set and pseudopotentials (PP) Computational Details. quantum ESPRESSO is distributed under the GNU (Gnu's Not Unix) General Public License (GPL), probably the most common freesoftware license. used a gradient corrected exchange and correlation energy functional (PBE), together with a plane-waves expansion of Kohn-Sham orbitals and electronic density, using ultra-soft pseudopotentials for all the elements involved. The plane-wave cut-off energy was chosen to be 35 (280) Ry for the wavefunction when evaluating the energetics of defects.

\section{Atomistic Modelling}

Supercell files are made with a Visualization For Electronic and Structural Analysis called VESTA. This package lets us build a supercell atom by atom.

\section{a. Supercell From $\beta "$ and $\beta$}

The phase $\beta$ (fluorite $\mathrm{Mg}_{2} \mathrm{Si}$ ) is the terminal equilibrium structure of the precipitation sequence. It has a fcc primitive unit cell (space group Fm-3m (225)), with an experimental lattice parameter $\mathrm{a}=6.39^{\circ} \mathrm{A}{ }^{[4]}$. It forms precipitates of a plate-like or cubic shape up to 20 $\mu \mathrm{m}$ in diameter. Its interface with the $\mathrm{Al}$ matrix is fully incoherent ${ }^{[8,10]}$. 


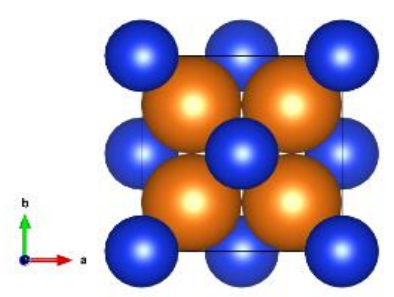

a.

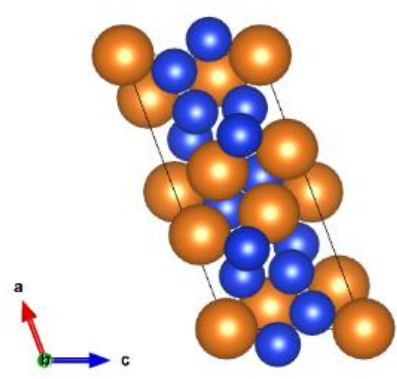

b.

Figure 1. (a) Precipitate Supercell model $\mathrm{Mg}_{2} \mathrm{Si}$ and (b) Precipitate Supercell model $\mathrm{Mg}_{5} \mathrm{Si} 6$

The $\beta^{\prime \prime}$ - Phasehas a base-centred-monoclinic conventional unit cell (space group $\mathrm{C} 2 \mathrm{~m}$ ) with experimental lattice parameters $\mathrm{a}=15.16 \AA, \mathrm{b}=6.74 \AA, \mathrm{c}=4.05 \AA$, and $\gamma_{\mathrm{ab}}=105.3^{0[8,11]}$

\section{b. Structural Relationship between $\beta "$ "-Mggis, $\beta$-Mg2 $\mathrm{Si}$ and $\alpha-\mathrm{Al}$}

Figure 2 illustrates the structural similarity between $\beta^{\prime \prime}-\mathrm{Mg}_{5} \mathrm{Si}_{6}$ and fcc $\alpha-\mathrm{Al}$ by showing a 22atom supercell of the a-Al fcc lattice in the form of a conventional monoclinic unit cell (CMUC) of $\beta^{\prime \prime}-\mathrm{Mg}_{5} \mathrm{Si}_{6}$.

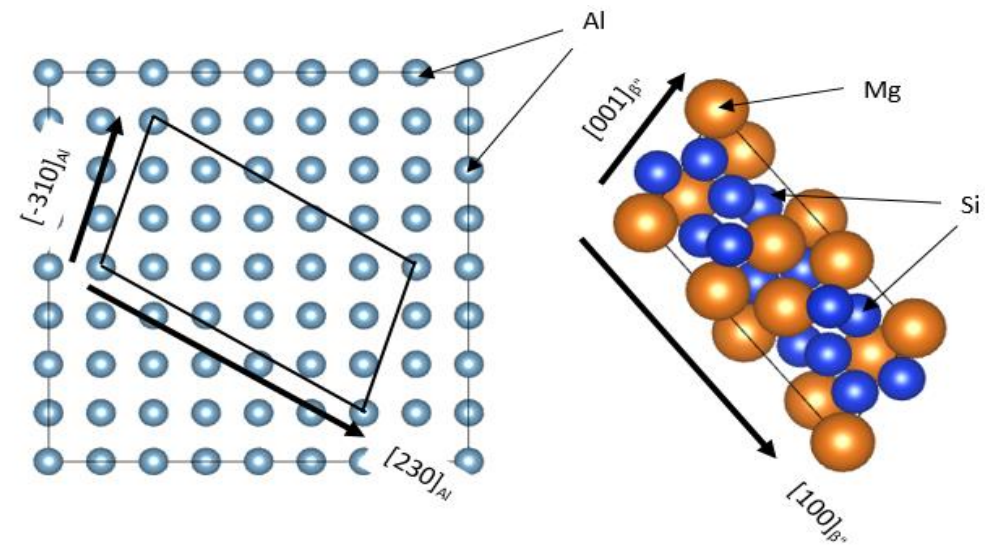

Figure 2. The crystal structure of Precipitate and its relation with $\alpha-\mathrm{Al}$

\section{c. Interfacial orientations}

The interfacial orientation relations for these four types of interfaces are summarized as follows:

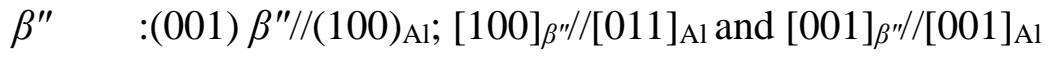

$$
\begin{aligned}
& \beta \quad:(100)_{\beta} / /(100)_{\alpha} ;[100]_{\beta} / /[100]_{\alpha}
\end{aligned}
$$

For bulk fcc Al, we computed the lattice parameter to be $4.057 \AA$, in excellent agreement with the experimental value and with previous modelling using the same functional ${ }^{[5]}$. These lattice parameters are used through out our study to build supercells representing the $\mathrm{Al}$ matrix. All of the $\beta^{\prime \prime}$ and $\beta$ phases we consider can be described by Interfacial orientations below.

To obtain higher quantitative accuracy for the interfacial energies, we use larger supercells, as shown in figure 


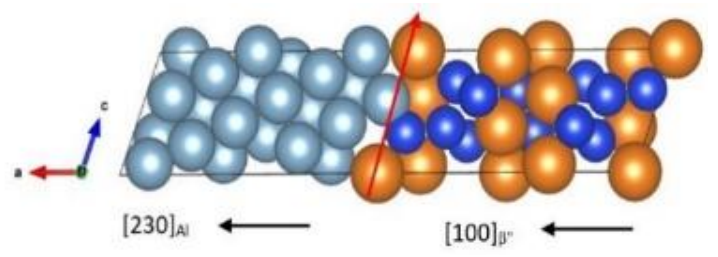

A1

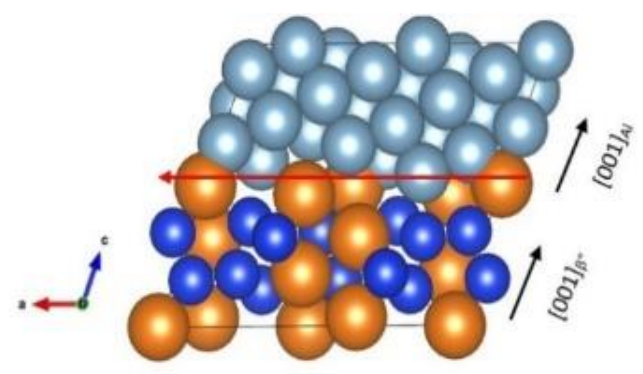

B1

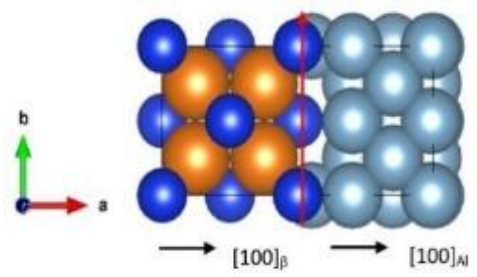

A2

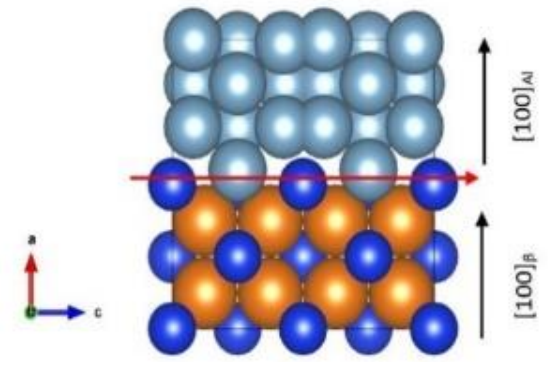

B2

Figure 3. (A1).Interface Alumunium $\alpha$ (fcc) - Precipitate $\beta^{\prime \prime}\left(\mathrm{Mg}_{5} \mathrm{Si}_{6}\right)\left[{ }_{230}\right]_{\mathrm{Al}} \|[100]_{\beta^{\prime \prime}}$.(A2).Interface Alumunium $\alpha$ (fcc) - Precipitate $\beta\left(\mathrm{Mg}_{2} \mathrm{Si}\right)[100]_{\mathrm{Al}} \|[100]_{\beta}(\mathbf{B 1})$.Interface Alumunium $\alpha$ (fcc) Precipitate $\beta^{\prime \prime}\left(\mathrm{Mg}_{5} \mathrm{Si}_{6}\right)[001]_{\mathrm{Al}} \|[001]_{\beta^{\prime \prime}}(\mathbf{B 2})$ Interface Alumunium $\alpha$ (fcc) - Precipitate $\beta\left(\mathrm{Mg}_{2} \mathrm{Si}\right)$ $[100]_{\mathrm{Al}} \|[100]_{\beta} \mathrm{Si}$ : blue ball, $\mathrm{Mg}$ : Orange Ball, Al : Gray ball.

We performed calculations on supercells for all interfacial orientations described above: for

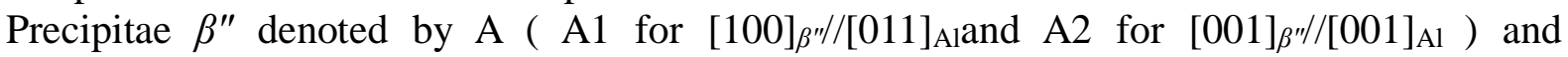
Precipitate $\beta$ denoted by B with $(100)_{\beta} / /(100)_{\alpha} ;[100]_{\beta} / /[100]_{\alpha}$.

\section{Bulk Properties Of Matrix And Precipitate Phases}

Bulk properties (lattice structure, lattice constants, elastic constants) of $\mathrm{Al}$ and the various $\beta^{\prime \prime}$ and $\beta$-precipitates studied here have been previously computed in the literature. Here, we present our results as a means of.

\section{a. The Solute Energies Element Precipitate}

In order to define a reference state for the thermodynamics of the precipitates we define the solid solution energies asbenchmarking our methods, verifying literature results, and most importantly obtaining reference values that are fully consistent with our computational details - which is crucial to evaluate the energy diferences that determine interface and Precipitate energies.

$$
\begin{aligned}
& E_{A l}^{S S}=\frac{E_{A l_{m}}^{t o t}}{M} \\
& E_{X}^{S S}=E_{A l_{M-1(x)}^{t o t}}^{t}-(M-1) E_{A l}^{S S}
\end{aligned}
$$

For $\mathrm{x}=\mathrm{Si}, \mathrm{Mg}$. Here, $E_{A l_{m}}^{\text {tot }}$ and $E_{A l_{M-1(x)}}^{\text {tot }}$ are the total energies of a bulk-Al supercell containing $\mathrm{M} \mathrm{Al}$ atom ad $(\mathrm{M}-1) \mathrm{Al}$ atom and 1 atom of $\mathrm{x}=\mathrm{Si}, \mathrm{Mg}$, respectively. The energy $E_{A l_{M-1(x)}^{t o t}}$ is computed using a single solute in a $2 \times 2 \times 2$ unit periodic call with the cell volum held fixed. 


\section{b. Precipitae Energy}

To be consistent with the denition of Precipiate energies used above, we define the precipitation energy using the SSSS as reference,

$$
E_{\text {prec }}(N)=\frac{E_{s y s}^{t o t}(N)-n_{a l} E_{A l}^{S S}-n_{M g} E_{M g}^{S S}-n_{S i} E_{S i}^{S S}}{\mathrm{~N}_{F u}}
$$

where $\mathrm{n}_{\mathrm{Al}}$ is the number of Atoms $\mathrm{Al}$ in the matrix for give simulation supercell, and $\mathrm{n}_{(\mathrm{Mg}, \mathrm{Si})}$ and $E_{(m g, S i)}^{S S}$ indicate the $\beta "$ compsition and the solid-solution energy for $\mathrm{Al}, \mathrm{Si}$ dan $\mathrm{Mg}$. $\mathrm{N}_{\mathrm{FU}}$ is the number of formula units in the precipitate cross-section.

\section{c. Interfece Energy}

It is common practice to talk of interfacial energy. In reality, however, what is usually meant and measured by experiment is the interfacial free energy, $\gamma$. The free energy of a system containing an interface of area $A$ and free energy $\gamma$ per unit area is given by

$$
\gamma=\frac{\text { Eprec }}{2 S_{\text {supercell }}^{\Lambda}}
$$

Where $S_{\text {supercell }}^{\Lambda}$ is the cross section of the simulation supercell corresponding to the orentation of the interface, $\mathrm{n}_{\mathrm{Al}}$ is the number of $\mathrm{Al}$ atoms in the Matrix, and $\mathrm{n}_{\beta}$, is the number of $\beta$ " formula units inside the supercell and $\gamma$ is Interface Energy.

\section{d. Strain Energy}

The Precipitate energy as defined in Eq. (1) thus contains both contributions from the interfacial energy, as well as the elastic strain energy from the lattice mismatch between Matrix and Precipitate. Specifically, the energy of formation of Eq. (1) can be expressed as

$$
\frac{\text { Eprec }}{N}=\frac{2 S_{\text {supercell }}^{\Lambda} \gamma_{\Lambda}}{N}+\sigma
$$

Where $\sigma$ is Strain energy and $\mathrm{N}_{\mathrm{FU}}$ is the number of formula units in the precipitate ${ }^{[9]}$.

\section{RESULTS AND DISCUSSIONS}

\section{a. Calulations Precipitate Energy}

The precipitate energy is the energy required to produce a defect (a vacancy) into the perfect crystal structure. In order to find the energetically most stable composition of $\beta^{\prime \prime}$. we compared the total energy of an Al supercell with an embedded precipitate to that of a solid solution containing the corresponding number of (noninteracting) solute atoms spread throughout the matrix. We quantified this by the precipitate energy, Energy of precipitate defined by Equation 3.

Table 1. calculated Precipitate energetics for the different Precipitate

\begin{tabular}{ccc}
\hline No & Name & $\begin{array}{c}\text { Precipitate Energy } \\
(\mathrm{eV})\end{array}$ \\
\hline 1 & A1 & $-1,843830596$ \\
2 & A2 & $-1,382719883$ \\
3 & A3 & $-2,129291747$ \\
4 & A4 & $-3,226849805$ \\
\hline
\end{tabular}


The lowest energy precipitate is precipitate energy of Interface Alumunium $\alpha$ (fcc) Precipitate $\beta^{\prime \prime}\left(\mathrm{Mg}_{2} \mathrm{Si}\right)$ [100]Al \| [100] $\beta$ with value $-1,382719883$ and the highest is precipitate energy of interface Alumunium $\alpha$ (fcc) - Precipitate $\beta\left(\mathrm{Mg}_{2} \mathrm{Si}\right)[100]_{\mathrm{Al}} \|[100]_{\beta} 1$ with value $-3,226849805 \mathrm{eV}$. while for Precipitate Energy of Interface Alumunium $\alpha$ (fcc) -

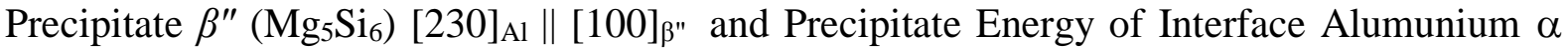
(fcc) - Precipitate $\beta^{\prime \prime}\left(\mathrm{Mg}_{2} \mathrm{Si}\right)[100]_{\mathrm{Al}} \|[100]_{\beta}$ has a value of $-1,843830596 \mathrm{eV}$ and $3.2726849805 \mathrm{eV}$ respectively. The precipitate energy required to produce a defect (a vacancy) into the perfect crystal structure, and to compare the energy precipitate which is owned by precipitate $\beta^{\prime \prime}$ and $\beta$, thatprecipitate $\beta$ have higher energy than precipitate $\beta "$. So precipitate $\beta$ is more stable and stronger in its crystalline structure compared to precipitate $\beta$ "which has a metastable structure.

\section{b. Calulations Interface Energy}

Interface energy comes from a mismatch in the bondings between phase 1 and phase 2 . When the interface is between two different phases there are usally three contributions to the free energy. The chemical-bonding and lattice strain-energy, and the cohesive energy of the separate phases, $E_{c}$. To compute the interface energy, $\gamma$ we must compute the total energy of the slab and subtract the constituents from it until we are left with the excess strain energy from the misfit, and the chemical interface energy. Small variations in the interfacial energy can lead to large variations in the predicted precipitation behaviour of an alloying system

Table 2. calculated Interface energetics for the different Precipitate

\begin{tabular}{cccc}
\hline No & Name & $\begin{array}{c}\text { The cross section of Interface } \\
\left(\AA^{2}\right)\end{array}$ & $\begin{array}{c}\text { Interface Energy } \\
\left(\mathrm{eV} / \AA^{2}\right)\end{array}$ \\
\hline 1 & A1 & 28.20806 & $-0,0326$ \\
2 & A2 & 61.1614 & $-0,0251$ \\
3 & A3 & 40.515389 & $-0,020281$ \\
4 & A4 & 104.16708 & $-0,015488$ \\
\hline
\end{tabular}

The interface energy be representation energy for The breaking of bonds of atoms of surface, The lowest value of the calculation is Interface Alumunium $\alpha$ (fcc) - Precipitate $\beta^{\prime \prime}\left(\mathrm{Mg}_{2} \mathrm{Si}\right)$ [100]Al $\|[100] \beta$ with $-0,015488 \mathrm{eV} / \AA^{2}$ and the highest is Interface Alumunium $\alpha$ (fcc) Precipitate $\beta^{\prime \prime}\left(\mathrm{Mg}_{5} \mathrm{Si}_{6}\right)$ [230]Al $\|[100] \beta^{\prime \prime}$ with value $-0,0326 \mathrm{eV} / \AA^{2}$ while for Interface Alumunium $\alpha$ (fcc) - Precipitate $\beta^{\prime \prime}\left(\mathrm{Mg}_{5} \mathrm{Si}_{6}\right)$ [001]Al $\|[001] \beta "$ and Interface Alumunium $\alpha$ (fcc) - Precipitate $\beta^{\prime \prime}\left(\mathrm{Mg}_{2} \mathrm{Si}\right)[100]_{\mathrm{Al}} \|[100]_{\beta} 1$ has a value of $-0,0251 \mathrm{eV} / \AA^{2}$ and $-0,020281$ $\mathrm{eV} / \AA^{2}$ respectively. The strongest interfaces are dominated by the presence of Aluminum and silicon bonds and based on the explanation of Chapter 3. The interface precipitate $\beta$ "and matrix aluminum are coherent, in contrast to the precipitate $\beta$ interface that has an interface that is incoherent with the aluminum matrix. Interface energy has this important role because Precipitate holds the atomic dislocation so that its mechanical properties increase, The barriers that block the dislocation can be generated during the deformation process, where the load will focus around the interface, resulting in an energy

strain around the interface between the precipitate and the matrix and the highest energy interface between precipitate $\beta$ "and precipitate $\beta$ is precipitate $\beta$ " thus mechanical properties will increase.

\section{c. Calculation Strain Energy}

In the molecule, strain energy is the energy stored by a system undergoing deformation, strain energy is released when the constituent atoms are allowed to rearrange themselves in a chemical reaction. The external work done on an elastic member in causing it to distort from 
its unstressed state is transformed into strain energy which is a form of potential energy. The strain energy in the form of elastic deformation is mostly recoverable in the form of mechanical work.

Table 3. Calculated Strain energetics for the different Precipitate

\begin{tabular}{ccc}
\hline No & Name & $\begin{array}{c}\text { Strain Energy } \\
(\mathrm{eV})\end{array}$ \\
\hline 1 & A1 & $-0,00463$ \\
2 & A2 & $-0,0371$ \\
3 & A3 & $-0,00628$ \\
4 & A4 & $-0,00012$ \\
\hline
\end{tabular}

Precipitate holds the atomic dislocation so that its mechanical properties increase, The barriers that block the dislocation can be generated during the deformation process, which causes the dislocation to accumulate and the movement to be obstructed, resulting in an energy strain around the interface between the precipitate and the matrix. From the results of the calculation of the simulation results obtained The highest energy Strain is Interface Alumunium $\alpha$ (fcc) - Precipitate $\beta^{\prime \prime}\left(\mathrm{Mg}_{5} \mathrm{Si}_{6}\right)$ [001]Al $\|[001] \beta^{\prime \prime}$ with value $-0,0371 \mathrm{eV}$ and the lowest is Strain Energy is Interface Alumunium $\alpha$ (fcc) - Precipitate $\beta^{\prime \prime}\left(\mathrm{Mg}_{2} \mathrm{Si}\right)$ [100]Al $\|$ $[100] \beta 2$ with value $-0,00012 \mathrm{eV}$.

\section{CONCLUSIONS}

The influence type of interfaces between precipitate and matrix aluminum, a coherent interface (Precipitate $\left.\beta^{\prime \prime}\right)$ to the matrix has a higher energy interface compared to an incoherent interface (precipitate $\beta$ ). Influence Interface orientation to energy interfaces and strain energy, on the precipitate $\beta$ " the highest interface energy is the Interface Alumunium $\alpha$ (fcc) - Precipitate $\beta^{\prime \prime}\left(\mathrm{Mg}_{5} \mathrm{Si}_{6}\right)$ [230]Al $\|[100] \beta "$ while for the highest Strain Energy is Interface Alumunium $\alpha$ (fcc) - Precipitate $\beta^{\prime \prime}\left(\mathrm{Mg}_{5} \mathrm{Si}_{6}\right)$ [001]Al \| [001] $\beta "$. While the precipitate $\beta$, interface energy and the largest strain energy is the Interface Alumunium $\alpha$ (fcc) - Precipitate $\beta\left(\mathrm{Mg}_{2} \mathrm{Si}\right)[100]_{\mathrm{Al}} \|[100]_{\beta}$. In the optimum aging state formed precipitate $\beta^{\prime \prime}$ with the chemical formula $\mathrm{Mg}_{5} \mathrm{Si}_{6}$. Based on the results of calculations and simulations, precipitate $\beta^{\prime \prime}$ has a lower precipitate energy in comparison with precipitate $\beta\left(\mathrm{Mg}_{2} \mathrm{Si}\right)$ which has a more stable energy precipitate. But precipitate $\beta$ has a lower energy interface in comparison with precipitate $\beta "$. The interface plays an important role in improving its mechanical properties. In the optimum aging state, the material will have the highest hardness value, because precipitate $\beta^{\prime \prime}$ has a higher energy interface, so it can hold the rate of deformation of atoms larger than the precipitate $\beta$.

\section{ACKNOWLEDGEMENTS}

This research was supported by the Department of Mechanical Engineering, Gunadarma University in Depok, Indonesia.

\section{REFERENCES}

1 George, E., Totten, \& Scott MacKenzie, D. 2003. Handbook of aluminum. Physical Metallurgy and Processes. New York: Marcel Dekker Inc.

2 Polmear, I. J. 1995. Light Alloys: Metallurgy of the Light Metals, Metallurgy and Materials Science Series, Arnold. 
3 Wenner, S., Marioara, C. D., Ramasse, Q. M., Kepaptsoglou, D. M., \& Hage, F. S. 2014. Atomic-resolution electron energy loss studies of precipitates in an $\mathrm{Al}-\mathrm{Mg}-\mathrm{Si}-\mathrm{Cu}-\mathrm{Ag}$ alloy. Scripta Materialia, Vol. 74, Hal. 92-95.

4 Giofré, D., Junge, T., Curtin, W. A., \& Ceriotti, M. 2017. Ab initio modelling of the early stages of precipitation in Al-6000 alloys. Acta Materialia, Vol. 140, Hal. 240-249.

5 Wang, Y. K., \& Chen, L. Q. 2007. First-principles calculations of $\beta$ "-Mg5Si6/ $\alpha-\mathrm{Al}$ interfaces." Acta Materialia, Vol. 55, No. 17, Hal. 5934-5947.

6 Ninive, P. H., Løvvik, O. M., \& Strandlie, A. 2014. Density Functional Study of the $\beta$ Phase in Al-Mg-Si Alloys. Metallurgical and Materials Transactions, Vol. A45, No. 6, Hal. 2916-2924.

7 Boyko, V. 2015. Characterization of the structure and precipitation process in Al-Mg-Si and Al-Mg-Ge casting alloys. Technische Universitet Berlin (Germany).

8 Frøseth, A. G., Høier, R., Derlet, P. M., \& Andersen, S. J. 2003. Bonding in mgsi and Al$\mathrm{Mg}-\mathrm{Si}$ compounds relevant to Al-Mg-Si alloys. Physical Review, Vol. B67, No. 22, 224106.

9 Ninive, P. H., Strandlie, A., \& Gulbrandsen-Dahl, S. 2014. Detailed atomistic insight into the $\beta$ phase in Al-Mg-Si alloys. Acta Materialia, Vol. 69, Hal. 126-134.

10 Davis, J. R. 1993. Aluminum and aluminum alloys. ASM international.

11 Marioara, C. D., Andersen, S. J., Zandbergen. 2005. The influence of alloy composition on precipitates of the Al-Mg-Si system. Metallurgical and materials transactions, Vol. A 36, No. 3. 